\title{
Ideological Consistency, Political Orientation, and Variability Across Moral Foundations
}

\author{
Tom Pyszczynski and Pelin Kesebir \\ University of Colorado at Colorado Springs \\ Matt Motyl
}

New York University - Stern School of Business \& University of Illinois at Chicago

Andrea Yetzer

Northwestern University

Jacqueline M. Anson

Central Methodist University

WORD COUNT: 9,981

Author note:

This material is based upon work partially supported by the National Science Foundation Graduate Research Fellowship Program under Grant No. (DGE-1419119). Any opinions, findings, and conclusions or recommendations expressed in this material are those of the author(s) and do not necessarily reflect the views of the National Science Foundation. Corresponding author: Tom Pyszczynski, tpyszczy@uccs.edu 


\begin{abstract}
We conceptualized ideological consistency as the extent to which an individual's attitudes toward diverse political issues are coherent among themselves from an ideological standpoint. Four studies compared the ideological consistency of self-identified liberals and conservatives. Across diverse samples, attitudes, and consistency measures, liberals were more ideologically consistent than conservatives. In other words, conservatives' individual-level attitudes toward diverse political issues (e.g., abortion, gun control, welfare) were more dispersed across the political spectrum than were liberals' attitudes. Study 4 demonstrated that variability across commitments to different moral foundations predicted ideological consistency and mediated the relationship between political orientation and ideological consistency.
\end{abstract}

Key words: Political ideology, political attitudes, liberals, conservatives, moral foundations theory 


\section{Ideological Consistency, Political Orientation, and Consistency Across Moral Foundations}

Why would people's attitudes toward government social programs give any indication of whether they believe that global climate change is occurring? Why do people's opinions about immigration predict whether they condone same-sex marriage? Despite their diverse content, the common thread underlying these issues is political ideology. To the extent that a person's diverse political attitudes consistently reflect a given position on the left-to-right political spectrum, they can be said to be "ideologically consistent." In this paper, we compare the levels of ideological consistency displayed by conservatives and liberals in early $21^{\text {st }}$ century America and then explore the role that consistency across moral foundations plays in predicting ideological consistency.

\section{Political Ideology}

Political ideology refers to an interrelated set of attitudes and beliefs, shared within a political group, that functions to organize, motivate, and direct political behavior (Jost, 2006). If the relationships among positions toward diverse political issues are predictable — for instance, if it can be predicted that someone who doubts global climate change would likely oppose social welfare programs - it is due to the structuring power of political ideology. Political ideologies bundle together attitudinal positions toward diverse issues and present them as over-arching frameworks that people use to guide voting and other policy-related attitudes and behaviors (Sniderman \& Bullock 2004). By simplifying a complex political landscape, political ideologies serve as organizing devices that fulfill a critical epistemic function (Jost, Federico, \& Napier, 2009; Knight, 2006). 
In two-party systems, political parties typically construct platforms that appeal to either liberal or conservative constituencies. For example, in American politics, the Democratic Party's platform reflects a left-leaning liberal stance and the Republican Party's platform a right-leaning conservative stance on the ideological spectrum. These platforms provide ideological cues and decision heuristics regarding issues that sometimes bear little logical relation to each other. Research shows that people are more likely to support a policy they believe is favored by their own party than one they believe is favored by the opposing party, regardless of the content of the policy (Cohen, 2003; Hawkins \& Nosek, 2012). Political elites (e.g., politicians, media pundits) construct ideological packages that are organized along a left-right, liberal-conservative spectrum, and citizens are thought to absorb the positions of elites with whom they identify (Clifford, Jerit, Rainey, \& Motyl, 2015).

\section{Psychological Differences between Conservatives and Liberals}

Political ideology is viewed as functioning to satisfy people's epistemic, existential, and relational needs (Hennes, Nam, Stern, \& Jost, 2012; Jost, Ledgerwood, \& Hardin, 2007). This implies that adherence to different ideologies should be associated with differences in the nature and extent of these needs. Consistent with this view, research has documented dispositional, motivational, and cognitive differences between conservatives and liberals.

In the most comprehensive review of psychological differences between conservatives and liberals to date, Jost, Glaser, Kruglanski, and Sulloway (2003) meta-analyzed 88 studies conducted in 12 countries over a 44-year period. Their results revealed that variables such as dogmatism, intolerance of ambiguity, needs for structure and closure, fear of threat and loss, and death anxiety correlated positively with adherence to conservative ideology. Liberalism, on the 
other hand, was associated with openness to new experiences, cognitive complexity, and tolerance of uncertainty. These core dispositional differences between conservatives and liberals reflect deep-seated values and beliefs, particularly regarding authority, inequality and social change (Jost et al., 2003). Self-professed conservatives are more likely than liberals to endorse traditional cultural values and religious forms of morality (Graham \& Haidt, 2010). This research suggests that whether one is drawn to conservative or liberal leaders and agendas reflects basic differences in "underlying psychological needs for stability versus change, order versus complexity, familiarity versus novelty, conformity versus creativity, and loyalty versus rebellion" (Jost, 2006, p. 662).

\section{Ideological Consistency}

There has been considerable debate among political scientists as to whether ordinary citizens actively use ideology to structure their political attitudes — and about the extent to which their attitudes are logical, coherent, and stable along ideological lines (e.g., Converse, 1964; Feldman, 2003; Kinder \& Sears, 1985). When asked to, people clearly are willing to place themselves on a scale representing the liberal-conservative continuum (Jost, 2006), and these self-placements, together with partisanship information, are among the most robust predictors of political preferences (Jacoby, 1991). However, Converse (1964) famously argued that the political attitudes of a great majority of the public lack the stability and connectedness that would be expected if they were rooted in sophisticated ideological conceptualizations. After a comprehensive review of the literature more than three decades later, Kinder (1998) similarly concluded: "Precious few Americans make sophisticated use of political abstractions. Most are mystified by or are at least indifferent to standard ideological concepts, and not many express 
consistently liberal, conservative, or centrist positions on government policy. Although the elites' views tend to be well-ordered, those of the rank-and-file public are not. Such ideological scatter is no less true during tumultuous and ideologically charged periods than in more serene times." (p. 796).

Even if most people are not sophisticated or committed ideologues, self-placement on a liberal-conservative ideological continuum is nonetheless predictive of a broad range of political and non-political attitudes, moral values, community preferences, and even how one organizes one’s office (e.g., Graham et al., 2013; Lewis-Beck, Jacoby, Norpoth, \& Weisberg, 2008; Motyl, 2014; Motyl, 2016; Motyl \& Iyer, 2014; Motyl, Iyer, Oishi, Trawalter, \& Nosek, 2014).

Baumeister (1991) pointed out that ideologies are psychological systems rather than logical systems that succeed not because they are logically elegant and free of internal contradiction, but rather because they serve important psychological functions, such as helping people interpret the events of their lives and evaluate things as good or bad. This implies that, even if their ideologies are not well-articulated, sophisticated, or consistent, ordinary citizens do possess political ideologies that serve important epistemic and existential functions and influence their attitudes and behavior.

Although subscribing to a political ideology necessitates some coherence, the extent of this consistency among attitudes toward political issues likely varies among people and is affected by both dispositional and situational forces. The purpose of the present work is to illuminate some of the determinants of this consistency. Previous research on the organization of political attitudes has studied the extent of this coherence under various labels, such as constraint, consistency, political attitude structure, and logical interrelationship. These all refer 
"to the degree of likeness, agreement, or fit characterizing the various elements or manifestations of an ideology" (Gerring, 1997, p. 974).

Research assessing predictors of ideological consistency among the general public has shown that education, political involvement and expertise are associated with higher ideological consistency (Jacoby, 1991; Judd, Krosnick, \& Milburn, 1981). Those who are highly involved in and/or informed about politics express attitudes that are more consistently structured and more reflective of a single underlying ideology. Jennings (1992), for example, found that the ideological consistency of political party elites (e.g., convention delegates) substantially exceeds that of the mass public. Ideological consistency also seems to be higher for abstract rather than concrete, and core rather than peripheral political issues (Jost, 2006).

To our knowledge, research has not yet examined variability in ideological consistency among the general public. The research reported here makes an important first step in this direction. However, Barton and Parsons (1977) assessed attitude structures among party elites and concluded that Republican politicians have more internally consistent beliefs than Democratic politicians. They also found a strong positive rank order correlation between conservatism and consistency. However, these findings do not address the question of how rankand-file conservatives and liberals differ in their ideological consistency. In addition, their study was conducted over 40 years ago and assessed only attitudes toward the economy and foreign policy; it is unclear whether their findings reflect the broad spectrum of issues that are central to contemporary American political ideology.

Against this background, the first goal of the present research was to examine whether self-placement across the liberal-conservative continuum predicts differences in ideological 
consistency. Consideration of psychological, cultural, and contextual forces leads to competing hypotheses as to whether conservatives or liberals would be more ideologically consistent. Why might conservatives display greater ideological consistency?

As reviewed earlier, right-wing conservatism is associated with intolerance of ambiguity, uncertainty avoidance, needs for structure and closure, as well as lower levels of openness to experience and integrative complexity (Jost et al., 2003). Though there is some evidence that hard-core leftists can be as cognitively rigid as hard-core conservatives (e.g., Tetlock, 1984), the consensus seems to be that today's American conservatives are drawn more to simple, unambiguous, and familiar stimuli than their liberal counterparts. Jost and colleagues (2009) write that "conservative styles and opinions are generally simpler, more internally consistent, and less subject to ambiguity, in comparison with liberal styles and opinions" (p. 320); and after a critical review of the literature, Tetlock (2007) pointed out that the data never show that "across issues, conservatives as a group score as more flexible and multidimensional than liberals" (p. 906). Drawing from research showing that approach (vs. avoidance) motivation is associated with broader conceptual attention and more diverse cognitive representations, Janoff-Bulman (2009) reached the same conclusion - that liberals' thinking might be more complex, given that liberals are higher on approach motivation and conservatives are higher on avoidance motivation (Janoff-Bulman, Sheikh, \& Baldacci, 2008). These multiple lines of research converge to suggest that conservatives would embrace a "purer" ideology and hold more consistent attitudes across diverse political issues.

Why might liberals display greater ideological consistency?

On the other hand, liberals might show more ideological consistency than conservatives 
because contemporary conservative ideology in the US reflects a broader coalition of interest groups with more diverse concerns that are less intrinsically related to each other than contemporary liberal ideology (Gottfried, 2009). Indeed, contemporary political discourse often differentiates between economic and social conservatives, foreign policy hawks, libertarians, tea party patriots, the religious right, proponents of unfettered capitalism, and even alt-right white nationalists (Crowson, 2009; Stenner, 2009). Similar distinctions are rarely, if ever, made in discussions of contemporary liberal ideology. Support for this view comes from studies by Feldman and Johnston (2009) and Weber and Federico (2013) that used mixed mode latent class analysis to show that self-identified conservatives fall into more distinct classes than selfidentified liberals.

Some have suggested that this relatively diverse coalition of conservatives may have emerged as a result of explicit attempts to bring together proponents of diverse issues in an attempt to counter the popularity of liberal politics in the wake of the social changes of the 1960's (Smith, 1990). The more recent fragmentation of the Republican party after their loss in the 2012 presidential election and the widely varying approaches to remedying this problem espoused by right wing pundits and politicians and such as Bill O'Reilly, Karl Rove, Jeb Bush, Rand Paul, Mike Huckabee, and Donald Trump (Bufkin, 2012; Siddiqui, 2012) might be another reason to expect less ideological consistency among conservatives than liberals.

In a related vein, the conservative mindset that resulted from this coalition might reflect a broader range of moral foundations that guide conservative than liberal ideology. Moral foundations theory (Haidt \& Graham, 2007; Haidt \& Joseph, 2004) posits that individual and cultural moral systems are built on a combination of five distinct moral intuitions - harm/care, 
fairness/reciprocity, ingroup/loyalty, authority/respect, and purity/sanctity. Research reveals that whereas liberals display higher endorsement and use of the harm/care and fairness/reciprocity foundations than the other three foundations, conservatives build their moral systems more evenly on all five foundations (Graham, Haidt, \& Nosek, 2009). This "broader morality" of conservatives, and the conflicting influences of these more diverse foundations, might lead them to display more within-person variability in their political attitudes than liberals.

Another reason conservatives might display lower ideological consistency reflects the underlying nature of conservatism as an ideology - conservatism emphasizes stability and the maintenance of institutions, values, and practices that are believed worthwhile. It entails a bias for the status quo (see Jost et al., 2003), and may be best understood not as a set of values centered around a substantive ideal and vision, but rather, as a reactive ideology — one born from the anxiety that established institutions and societal foundations are endangered by contemporary developments or proposed reforms (Huntington, 1957; Muller, 1997). As the content of what is to be conserved is constantly changing, conservatism manifests itself in different ways across time and place.

Consistent with this analysis, research finds that most issues that conservatives of previous eras vehemently opposed are no longer of concern to modern conservatives. Sugar, Viney, and Rohe (1992), for instance, demonstrated that participants who identified themselves as conservatives and had conservative views on contemporary issues, overwhelmingly supported many programs and legislations that were once regarded as liberal, such as child labor laws, voting rights for women, racial integration, the admission of women and African-Americans into universities, the smallpox vaccine, Social Security, and Medicare. Using public opinion data, 
Nosek, Banaji, and Jost (2009) demonstrated that whereas liberals' and conservatives' explicit attitudes toward African-Americans were most differentiated in the 1970's, by 2004 conservatives had "caught up" to where liberals had been for three decades. As issues that were originally resisted become part of the status quo, conservatives' opposition to them subsides and oftentimes disappears. For present purposes, this implies that individual adaptation to the status quo and shifts toward liberalism occur at varying speeds for different individuals and issues. This could lead to lower ideological consistency among conservatives.

If conservative ideas are based on defending the status quo and reacting to change, it is also possible that conservative ideologies exemplify more purist, absolutist, or extreme stances. For example, some conservative ideas, such as making abortion illegal under any circumstances or rejecting any change to existing gun laws can be construed as more extreme than the liberal alternatives for these issues. This suggests that, at least on some issues, conservative attitudes would be closer to the liberal, less extreme side of the scale. Supporting this, Zell and Bernstein (2013) recently found that young adults in general, but particularly conservatives in the U.S., rate themselves as more conservative than their actual attitudes relative to population norms suggest they are. This too could lead conservatives to display lower ideological consistency than liberals, since their attitudes embody a mix of conservative and liberal stances.

In sum, current theory and research in social and political psychology suggest competing hypotheses regarding the relationship between ideological orientation and ideological consistency. On the one hand, conservatives' predilection for simple, unambiguous, and structured information could lead them to possess more ideologically coherent and less conflicting attitudes toward political issues. On the other, the idea that conservative ideology 
reflects a broader range of interests and/or moral foundations suggests that ideological consistency would be greater among liberals than conservatives. A gradual historical shift toward liberal ideas and the notion that some conservative ideas are too extreme to be widely adopted even by self-identified conservatives similarly suggests that conservatives might display lower levels of ideological consistency than liberals. Our own intuition (and that of all colleagues with whom we discussed this research) was that conservatives would display higher ideological consistency than liberals.

\section{The Present Research}

The studies reported here tested, in four different samples with three different measures of political attitudes, whether self-identified liberals and conservatives differ in ideological consistency. After indicating their political orientation (i.e., conservative vs. liberal), party affiliation, and for whom they voted in the last election, participants responded to items assessing attitudes on diverse contemporary political issues that have clear conservative and liberal positions. Ideological consistency was operationalized in two ways: the within-person standard deviation of responses given on the political attitudes questionnaires and the percent of responses to the issues for which participants "cross the aisle" and endorse positions inconsistent with their political orientations. Because there are, to our knowledge, no existing measures of ideological consistency, and in order to make the issues assessed correspond to issues being debated at the time the studies were being conducted, we constructed our own attitudinal measures with an eye toward sampling a diverse range of issues for which there was clear differentiation between liberal and conservative positions. To increase the generality of our findings and hopefully show 
that the results are not due to specific issues and questions, we used different sets of opinion items across the various studies. The studies were conducted between late 2008 and late 2011.

\section{Study 1: Method}

Participant and procedure. Participants were 347 undergraduate students ( 275 females, 72 males $)$ who received class credit for their participation $\left(M_{\text {age }}=22.14 ; S D=5.74\right)$. The study was presented online as an investigation of personality and political attitudes. After reading instructions and providing informed consent, participants and completed the measures described below, after which they were debriefed.

Materials. Political ideology was assessed in three ways: self-ratings of political orientation on a 7-point Likert scale $(1=$ extremely conservative, $7=$ extremely liberal $)$, political party affiliation (Republican, Democrat, Other, or Not Affiliated), and for whom participants voted in the last presidential election (John McCain, Barack Obama, Other, or Decline to Answer).

Attitudes toward specific political issues were assessed with a 12-item Political Attitudes Questionnaire (PAQ). Participants indicated on 6-point Likert scales $(1=$ Strongly Disagree, $6=$ Strongly Agree) their agreement with statements such as "It is the responsibility of political leaders to promote programs that will help close the income gap between rich and the poor," and "The traditional (male/female) two-parent family provides the best environment of stability, discipline, responsibility and character" (see Appendix A for the complete list of items). The scale yielded good reliability (Cronbach's alpha $=.83$ ); higher scores denoted conservative attitudes.

\section{Results and Discussion}


The mean political orientation score was at the mid-point of the scale $(M=4.01, S D=$ 1.46), indicating a balanced distribution; $39.2 \%$ were moderate, $29.1 \%$ conservative, and $31.7 \%$ liberal. Political party affiliation was described as Republican by $33.7 \%$ and Democrat by $28 \%$; 37.5\% had voted for John McCain and 40.1\% for Barack Obama. As expected, average scores on the PAQ $(M=3.07, S D=.83)$ correlated substantially and in the expected direction with selfreported political orientation, $r(334)=-.66, p<.001$. Similarly, the scale yielded significant attitude differences in the expected directions between self-described Republicans $(M=3.63, S D$ $=.64)$ and Democrats $(M=2.50, S D=.73), t(205)=11.92, p<.001$, Cohen's $d=1.65$, and between those who voted for McCain $(M=3.58, S D=.64)$ and Obama $(M=2.48, S D=.72)$, $t(257.68)=13.11, p<.001, d=1.62 .^{1}$ These findings suggest that the items validly tapped into attitudes associated with the different political orientation.

Ideological consistency scores were computed for each participant by taking the standard deviation (SD) of their responses to the 12 items on the PAQ. Ideological consistency scores $(M$ $=1.19, S D=.38)$ and self-reported political orientation were significantly correlated, $r(334)=$ $-.24, p<.001$, with self-reported conservatism associated with lower ideological consistency, that is, with higher within-person attitudinal variability (see Figure 1$){ }^{2}$ Dropping participants from the analysis who identified themselves as moderate increased the association between ideological consistency and ideological orientation, $r(203)=-.31, p<.001$. The ideological consistency of those who placed themselves on the conservative side of the political orientation scale $(M=1.32, S D=.31)$ was significantly lower than those who placed themselves on the liberal side $(M=1.09, S D=.41), t(197.22)=-4.55, p<.001, d=0.63,95 \% \mathrm{CI}=[0.13,0.33]$. Moderates fell between liberals and conservatives $(M=1.17, S D=.37)$ and differed significantly 
from conservatives, $t(227)=-3.31, p=.001, d=0.45$, but not from liberals. Gender did not exert a significant effect on attitudinal variability or interact with the political orientation measures.

It could be argued that our within-person variability measure reflects a response bias to use a certain portion of the scale. To remedy this ambiguity and to assess the robustness of our findings across different measures of ideological consistency, we created a second operationalization of ideological consistency consisting of the percentage of items for which participants "crossed the aisle" and endorsed attitudes inconsistent with their political orientation. Doing this required excluding participants who identified as moderates by choosing the mid-point of the political orientation scale. For the remaining 211 participants, we computed the percentage of attitude items for which each participant agreed with the liberal or conservative position on the scale, and then transformed this to percent of items for which each participant agreed with their own and the opposite ideology. Replicating our previous findings, analyses using these percentages revealed that conservatives were significantly more likely to cross the aisle and agree with the liberal side of the scale $(39.63 \%$ of the time, $S D=19.41)$, than were liberals to agree with the conservative side $(23.91 \%, S D=18.71), t(203)=5.90, p<.001, d=$ $0.83,95 \% \mathrm{CI}=[10.47,20.97]$. As expected, percentage of agreement with the opposite ideology correlated significantly with our standard deviation across items measure, $r(203)=.33, p<.001$. However, the moderate magnitude of this correlation suggests that these measures capture different aspects of our conceptual variable, ideological consistency. Operationalized either way, conservatives showed lower ideological consistency than liberals.

\section{Study 2: Method}


Study 2 was identical to Study 1 in design, measures, and procedures, and was conducted to assess the robustness of the findings. Participants were 271 undergraduates (193 females, 78 males) with a mean age of $21.55(S D=5.26)$ who participated online in exchange for class credit.

\section{Results and Discussion}

The mean political orientation score was again very close to the mid-point of the scale ( $M$ $=4.05, S D=1.49) .40 .6 \%$ identified as moderate, $27.7 \%$ conservative, and $31.7 \%$ liberal. Political party affiliation was described as Republican by $31 \%$ and Democrat by $33.6 \%$. 35.8\% had voted for John McCain and 41\% for Barack Obama in the previous election. Thus, the sample was reasonably balanced in terms of political orientation.

Ideological consistency (i.e., intra-individual SD across attitude items) and self-reported political orientation correlated significantly $r(269)=-.23, p<.001$, with conservatism again associated with lower ideological consistency. Excluding self-identified moderates again increased the strength of this correlation, $r(159)=-.30, p<.001$. Conservatives $(M=1.30, S D=$ .38) again were less ideologically consistent than either liberals $(M=1.07, S D=.34), t(159)=$

$4.165, p<.001, d=0.63,95 \% \mathrm{CI}=[0.12,0.35]$, or moderates $(M=1.15, S D=.37), t(183)=$ $2.80, p=.006, d=0.42$, who did not differ from each other. The same pattern emerged on the "crossing-the-aisle" measure: conservatives $(41.78 \%, S D=16.64)$ were more likely to agree with the opposing side on particular issues than liberals $(28.00 \%, S D=19.21), t(159)=4.83, p<$ $.001, d=0.76,95 \% \mathrm{CI}=[8.14,19.41]$.

\section{Study 3: Methods}


Because the data in Studies 1 and 2 came from student populations, we conducted Study 3 with a different type of sample and with a different measure of political attitudes to increase generalizability.

\section{Method}

Participants and procedure. American participants (89 males, 87 females; $M_{\text {age }}=33.52$, $S D=12.50)$ were recruited using Amazon's Mechanical Turk in exchange for a small monetary payment. Ethnically, $81.3 \%$ of the participants reported being Caucasian, $9.7 \%$ Asian, $4.5 \%$ African American, 2.8\% Hispanic, and 0.6\% Native American. The remaining 1.1\% indicated other. The instructions and procedures of the study were the same as previous studies.

Materials. Participants completed a new Political Attitudes Questionnaire (PAQ- II), created for the current study, consisting of 28 items assessing attitudes on 14 politically loaded issues (see Appendix B). For each issue, participants indicated their agreement with two statements on a 7-point Likert Scale ( $1=$ Strongly Disagree, $7=$ Strongly Agree $)$, one stating the conservative position (e.g., "The government should keep out of health care") and one stating the liberal position (e.g., "The government should provide equal health care benefits for all, regardless of their ability to pay"). The 14 issues were health care, same-sex marriage, abortion, gun control, welfare, government's role in religion, global climate change, the Bush administration's policy on terrorism, assisted suicide, death penalty, alternative energy sources, Muslims, torture, and immigration. The scale was recoded so that high scores indicated liberal attitudes $($ Cronbach's alpha $=.94)$. Finally, participants indicated their political orientation, party affiliation, and for whom they voted in the last presidential election.

\section{Results and Discussion}


The mean political orientation score in this sample was $4.28(S D=1.67) .24 .4 \%$ identified as moderate, $30.8 \%$ conservative, and $44.8 \%$ liberal. Political party affiliation was described as Republican by $19.9 \%$ and Democrat by $38.6 \% .18 .8 \%$ had voted for John McCain and $51.7 \%$ for Barack Obama in the previous election.

Our within-participant SD measure of ideological consistency again correlated significantly with political orientation, $r(170)=-.21, p=.007$, with conservatism associated with lower ideological consistency (greater within-person variability in attitudes) than liberalism. Excluding self-rated moderates again strengthened the association between political orientation and ideological consistency, $r(128)=-.24, p=.006$, and conservatives $(M=1.86, S D=.47)$ showed lower consistency than liberals $(M=1.65, S D=.57), t(128)=2.21, p=.03, d=0.39$, $95 \% \mathrm{CI}=[0.02,0.40]$, and marginally lower consistency than moderates, $(M=1.67, S D=.53)$, $t(93)=1.80, p=.076, d=0.37$. Liberals and moderates did not differ from each other in their ideological consistency. Neither gender, nor age was associated with ideological consistency or interacted with any of the measures of political orientation in this sample.

The same results emerged on the crossing the aisle measure. Because the PAQ II assessed attitudes on a 7-point scale, we tabulated how frequently liberals and conservatives agreed with their own side, the other side, and the mid-point of the scale. Results again revealed that conservatives agreed more often with the liberal side of the scale $(30.19 \%, S D=17.14)$ than liberals agreed with the conservative side $(19.76 \%, S D=15.08), t(128)=3.66, p<.001, d=$ $0.65,95 \% \mathrm{CI}=[4.80,16.06]$. Looked at differently, conservatives agreed less with the conservative side of the scale $(59.30 \%, S D=19.74)$ than liberals agreed with the liberal side 
$(69.57 \%, S D=19.98), t(128)=-2.90, p=.004, d=0.52,95 \% \mathrm{CI}=[3.25,17.30]$. Conservatives and liberals did not differ in terms of how often they chose the middle point of the scale.

Study 3 replicated the findings from Studies 1 and 2 in a non-student sample and with a different measure of political attitudes. Across all three studies, conservatives, as defined by selfreports of political orientation, political party affiliation, and voting record consistently displayed attitudes toward political issues that were more scattered across the political spectrum and more likely to cross over to the opposing ideological position than liberals.

Given our surprise at these results (and that of our colleagues), we wondered whether the general public shared our expectations on this issue and whether these faulty expectations might depend on one's own political orientation. We thus conducted an online survey to assess the expectations of the lay public (103 participants) regarding whether conservatives or liberals are more ideologically consistent. The results showed that participants were about evenly split between judging conservatives to be higher in ideological consistency (43.7\%) and judging no difference between these groups (41.7\%). Those judging liberals as more consistent (14.6\%) were significantly less common, $\chi^{2}(2, N=103)=16.39, p<.001$. Participants' own political orientation was not related to these judgments, $\chi^{2}(2, N=78)=2.13, p=.34$. These findings illuminate lay perceptions regarding ideological consistency among liberals and conservatives and underscore the surprising nature of these findings.

In addition to contradicting our own intuitions, those of our colleagues, and those of the lay public, the findings of these three studies run counter to reasoning that the higher need for structure and dogmatism, and lower tolerance for ambiguity and openness to experience, typical of political conservatives, would lead conservatives to exhibit especially high levels of 
ideological consistency. Our findings were consistent, however, with the idea that conservative ideology in contemporary American society is rooted in a more diverse set of interests, values, or moral foundations than liberal ideology. This fits well with contemporary discussions of multiple factions (e.g., economic, social, libertarian) and divisiveness within the conservative movement in the U.S. and more diverse moral foundations underlying conservative ideology. These factors - which we view as quite consistent and compatible with each other - may have overwhelmed personality differences between liberals and conservatives, and thus led to higher levels of ideological consistency among liberals than conservatives in the present research.

\section{Study 4}

From the perspective of moral foundations theory (MFT; Haidt \& Graham, 2007; Haidt \& Joseph, 2004), political attitudes are inextricably linked to religious and secular notions of morality. Research has shown differences in the way liberals and conservatives structure their moral perceptions, with liberals weighing issues involving fairness and care concerns more heavily, and conservatives being more equally committed to all five moral foundations (Graham, Haidt, \& Nosek, 2009; Haidt \& Graham, 2007; cf. Frimer, Tell, \& Motyl, 2016).

The findings that conservatives are less ideologically consistent than liberals may therefore be a function of the foundational differences in liberals' and conservatives' moral intuitions. In this study, we aimed to investigate the mediating role of moral consistency in the relationship between political orientation and ideological consistency. Consistent with the findings of Studies 1-3, we hypothesized that higher levels of self-reported conservatism would be negatively related to ideological consistency, and that this relationship would be mediated by greater consistency in the importance placed on all five moral foundations. Looked at 
differently, we predicted that higher levels of self-reported liberalism would be positively related to ideological consistency, and that this relationship would be mediated by lower moral consistency.

Previous demonstrations of differences in the importance placed on the various moral foundations by liberals and conservatives assessed mean level of endorsement across individuals of each foundation, and found that whereas liberals endorse higher levels of harm/care and fairness/reciprocity than the other three foundations, conservatives tend not to differ in their level of endorsement across the five foundations (Graham, Haidt, \& Nosek, 2009). However, to the extent that the conservative movement in contemporary American society reflects a more diverse coalition of different interest groups (social, economic, tea party, etc.), it is possible that previous findings reflect different conservative individuals favoring different foundations over others; thus, the lack of difference among foundations may exist on an aggregate level but not on an individual level. By assessing within-person variability in endorsement of the five moral foundations this alternative explanation for previous findings possibility can be assessed. More germane to present concerns, it also provides a straightforward way of assessing the possibility that a difference in variability across moral foundations mediates the relationship between political orientation and ideological consistency.

Finally, the current study tested our hypotheses with a larger sample than the previous studies, which provided us with higher power that enabled us to assess other aspects of the relationship between political orientation and ideological consistency. Specifically, we examined the relationship between ideological consistency and the importance placed on each of the five moral foundations, all of which have been shown to be associated with political orientation. 


\section{Study 4: Method}

Participants. Participants were 1,478 adults residing in the United States drawn from a larger database of volunteers at http://www.yourmorals.org. All participants had previously registered at the site and provided demographic information, including age $(M=37.05, S D=$ 15.30), gender (61.8\% male), and interest in politics $(M=1.60, S D=.56$ on a scale from 0 [not much interested] to 3 [very much interested]); $95.6 \%$ of the sample reported they were somewhat to very much interested in politics. Political orientation was measured on a 7-point Likert scale ranging from 1 (very liberal) to 7 (very conservative) with the sample representing a more liberal orientation $(M=2.78, S D=1.64)$; and on categorical measure, in which participants chose from one of three options. On this measure, $72.7 \%$ identified as liberal, $10.5 \%$ as moderate, and 16.8\% as conservative. Participants reported their race/ethnicity as: White (86.5\%); Asian (5.3\%), Latino (4.1\%), African-American (2.1\%), Native American (2.1\%), Middle-Eastern (1.3\%), and declined (3.9\%). Education levels were reported as: graduate/professional degree (24.4\%), completed college/university degree (22.9\%), some college (12.4); thus, the sample was relatively highly educated, with $55.1 \%$ reporting at least some college, which is common for online samples.

Materials. In visiting the yourmorals.org site, participants self-select to take one or more surveys from a list of approximately 30 various scales and questionnaires. Here we report results for participants who completed a questionnaire measuring moral intuitions and questions related to political attitudes.

Moral Foundations Questionnaire. The Moral Foundations Questionnaire (MFQ; Graham et al., 2011) is a two-part 30-item measure used to assess the degree to which an 
individual endorses each of the five types of moral concerns: fairness/reciprocity, harm/care, ingroup/loyalty, authority/respect, and purity/sanctity (see Graham et al., 2011 for psychometric properties; referred to as harm, fairness, ingroup, authority, and purity from here on out). In the first part of the measure, participants rate 15 concerns on a scale from 0 (not at all relevant) to 5 (extremely relevant) to themselves when making moral judgments. Items include concerns such as, "Whether or not someone cared for someone weak or vulnerable" (harm) and "Whether or not someone showed a lack of respect for authority" (authority). In the second part of the measure, participants rate their agreement or disagreement with 15 statements representing the five different foundations using a scale from 0 (strongly disagree) to 5 (strongly agree); for instance, "It can never be right to kill a human being" (harm) and "People should not do things that are disgusting, even if no one is harmed" (purity). Six items representing each of the five foundations were averaged to create respective subscale means. Subscale statistics were as follows: Harm $(M=3.54, S D=.85$, Cronbach's $\alpha=.72)$, Fairness $(M=3.64, S D=.73, \alpha=.66)$, Ingroup $(M=2.25, S D=.87, \alpha=.71)$, Authority $(M=2.24, S D=.94, \alpha=.76)$, and Purity $(M=$ $1.59, S D=1.13, \alpha=.85)$.

Political attitudes. An 8-item Political Attitudes Questionnaire (PAQ- III) assessing endorsement of currently-debated political issues (see Appendix C) was used. Participants rated their degree of support for each issue on a 7-point Likert scale from 1 (strongly oppose; very unfavorable; a very bad thing) to 7 (strongly support; very favorable; a very good thing). Questions (e.g., "Do you feel bank regulation is a good idea?") were presented in random order and covered an array of topics, including same-sex marriage, abortion, legalization of marijuana, immigration, off-shore drilling, construction of a mosque near the former site of the World Trade 
Center, and bank regulation. Some items were reverse scored so that in all cases higher scores indicated more conservative attitudes. The measure demonstrated good internal reliability $(\alpha=$ $.85)$.

\section{Results and Discussion}

Ideological consistency scores and crossing the aisle measures were computed from the PAQ-III $(M=1.24, S D=.64)$ in accordance with Studies 1-3. As in the previous three studies, ideological consistency was correlated with liberalism on the continuous political orientation measure, $r(1476)=.51, p<.001$. Liberals again displayed greater ideological consistency (less within-person variability across attitudes) than conservatives. Analyses using the crossing-theaisle measure yielded similar results. Participants who categorized themselves as conservative were significantly more likely to agree with the liberal side of the scale $(34.79 \%$ of the time, $S D$ $=24.70$ ), than those who categorized themselves as liberal were likely to agree with the conservative side $(5.17 \%$ of the time, $S D=10.68), t(268.64)=-18.49, p<.001, d=1.56,95 \%$ $\mathrm{CI}=[-32.76,-26.48]$. Again, percent agreement with the opposite ideology correlated significantly with our standard deviation across items measure, $r(1321)=.65, p<.001$.

A similar intra-individual standard deviation (SD) computation was employed to create a measure of variability across moral foundations (VAMF). Rather than calculating mean scores for each MF as in previous studies, our VAMF measure consisted of the intra-individual SD across the five moral foundation subscale means to indicate the variability in how individuals weigh moral concerns across the five foundations. VAMF scores $(M=1.13, S D=.47)$ and selfreported political orientation were negatively correlated, $r(1476)=-.59, p<.001$, with selfreported conservatism associated with lower VAMF (i.e., smaller within-person variability 
across foundations). In other words, higher levels of conservatism were significantly related to more consistent endorsement across the five moral foundations. This is consistent with previous findings that conservatives show more equal endorsement of diverse moral foundations than liberals when averages of score on the five foundations across individuals are compared with each other (Graham et al., 2009; Haidt \& Graham, 2007), and rules out the alternative explanation that these findings reflect different conservative individuals endorsing different foundations that average out to show equivalent levels of commitment to the foundations.

More germane to the focus of the present research, VAMF was correlated with ideological consistency, $r(1476)=-.43, p<.001$. That is, greater variability across moral concerns was associated with lower within-person variability in political attitudes. Looked at differently, individuals whose morality is based on a broader range of similarly endorsed foundations are less ideologically consistent with respect to a range of political attitudes. This might be because their political views need to accommodate a greater number of equally valued moral concerns.

To investigate whether VAMF mediated the relationship between political orientation and ideological consistency found in Studies 1-3, we used the PROCESS macro for SPSS (version 2.16; Hayes, 2013) to perform a bootstrapping analysis (model 4; 10,000 bootstrap samples) to test the indirect effect of self-reported political orientation on ideological consistency through VAMF. Variables were mean-centered for the analysis (Aiken \& West, 1991) and we obtained bias-corrected bootstrapped confidence intervals for the indirect effect.

Consistent with the correlational findings, political orientation significantly predicted VAMF, $b=-.17, S E=.01, t(1475)=-29.01, p<.001$, with greater conservatism associated with 
lower VAMF (i.e., less variability in endorsement levels for the various moral foundations). Political orientation accounted for $35 \%$ of the variance in VAMF. Also consistent with the simple correlational analyses, VAMF was significantly related to ideological consistency, $b=$ $.28, S E=.04, p<.001$, such that greater VAMF was associated with more ideological consistency (lower within-person variability across attitudes). As predicted, there was a significant indirect effect of political orientation on ideological consistency through VAMF, $b=$ .05 , bootstrap $S E=.01, \mathrm{BCa} C \mathrm{CI}[0.03,0.06]$. When VAMF was included as the mediator, the direct effect of political orientation on ideological consistency remained significant, $b=.15, S E$ $=.01, t(1475)=13.44, p<.001 ;$ the model accounted for $29 \%$ of the variance in ideological consistency. Using the completely standardized indirect effect (Hayes, 2013; Preacher \& Kelley, 2011), this represents a medium effect, $a b_{p s}=.12$, bootstrap $S E=.02,95 \%$ BCa CI [.09, .15]; the mediator accounted for approximately one-fourth of the total effect, $P_{M}=.23$ (Preacher \& Kelley, 2011). These analyses suggest that the relationship between political orientation and ideological consistency was partially accounted for by VAMF (see Fig. 1).

Moral foundation importance. To determine if, as in previous research (Graham et al., 2009), liberals and conservatives differ in the importance they place on the five moral foundations, we conducted a 3 (political category: liberal, moderate, conservative) x 5 (moral foundation: harm, fairness, ingroup, authority, purity) mixed ANOVA, with moral foundation treated as a within-participant variable ${ }^{3}$. We found significant main effects of moral foundation $F(3.05,4491.46)=544.76, p<.001$, partial $\eta^{2}=0.27$, and political category $F(2,1474)=84.98$, $\mathrm{p}<.001$, partial $\eta^{2}=0.10$, as well as a political category $\mathrm{x}$ moral foundation interaction, $F(6.09$, 4491.46) $=308.09, p<.001$, partial $\eta^{2}=0.30$ (see Table 1 for means and standard deviations). 
As may be seen in Fig. 2, liberals placed greater importance on harm and fairness than moderates, who placed more importance on harm and fairness than conservatives. On the other hand, conservatives placed more importance on loyalty, authority, and purity than moderates, who placed more importance on all three of these foundations than liberals, respectively (see Table 2 for planned contrasts). Fig. 2 also shows that liberals showed the largest, and conservatives the smallest, differences in endorsement of the different moral foundations, with moderate falling in between these extremes.

To assess the relationship between the importance placed on each moral foundation and ideological consistency, we conducted a multiple regression, with ideological consistency scores as the criterion variable and political orientation and scores for importance placed on each of the five moral foundations as predictors; predictors were mean-centered prior to the analysis (Aiken \& West, 1991). As may be seen in Table 3, this analysis revealed that political orientation was a significant predictor of ideological consistency, along with and the harm, authority, and purity (but not the fairness or ingroup) foundations. As would be expected based on previous research showing that the individuating foundations are associated with liberal political orientation and the binding foundations are associated with conservative political orientation (Graham et al. 2009), high levels of importance placed on harm was associated with more ideological consistency and high levels of importance placed on authority and purity were associated with less ideological consistency.

In line with research highlighting variability in endorsement of moral concerns as a function of political orientation (e.g., Graham et al., 2009), these results shed light on why political conservatives were found to be less ideologically consistent than liberals in all four 
studies reported here. Liberals show more variability in the importance they place on the various moral foundations; this is consistent with previous research (replicated in this study) showing that whereas liberals place greater importance on the care and fairness foundations over the other foundations, conservatives are more consistent in the importance they place on the various foundations. This greater variability across the five foundations was associated with greater ideological consistency. Looked at differently, conservatives, who vary less in the importance they place on the different foundations, showed lower levels of ideological consistency, and thus greater variability in their endorsement of positions typically associated with a given political ideology. This difference in VAMF mediated the relationship between political orientation and ideological consistency.

Study 4 also rules out an important alternative explanation for previous findings regarding the relationship between political orientation and endorsement of moral foundations. Because previous research compared the average levels of moral foundation endorsement across participants who were liberal and conservative, it is possible that those findings are due to different conservative participants placing different levels of importance on different foundations, which average out to roughly equivalent levels of endorsement across the foundations at an aggregate level but do not reflect less variability in endorsement of the foundations within individuals. The present findings of greater individual level moral consistency among conservatives rules out this possibility and provides converging evidence for the conclusions drawn by Graham et al. (2009) and others.

\section{General Discussion}


Across four studies, conducted on student and non-student samples, using three different measures of political orientation and attitudes and two different operationalizations of ideological consistency, liberals consistently displayed higher levels of ideological consistency than conservatives, with moderate to large effect sizes. These findings were counter to our own intuitions, those of all colleagues asked to speculate about this relationship, and those of a lay sample recruited online, as well as reasoning derived from previous research showing conservatives to be higher than liberals in need for structure and dogmatism and lower in tolerance for ambiguity and openness to experience (Jost et al., 2003). They were consistent, however, with the recent research showing that conservatives rely on a broader range of moral intuitions to inform attitudes and behavior than liberals (Graham et al., 2009; Nosek et al., 2009).

Previous research (e.g., Graham et al., 2009) has demonstrated aggregate differences between the moral foundations endorsed by liberals and conservatives, with liberals valuing care and fairness above the other three foundations and conservatives not differing in their endorsement of the various foundations. Study 4 replicated these findings and added to them by showing that liberals were more variable in their within-individual endorsement of the foundations than conservatives, and that this difference mediated the relationship between political orientation and ideological consistency. Thus, liberals' higher VAMF was at least partially responsible for their higher levels of ideological consistency than conservatives. Given their commitment to fewer moral foundations, liberals presumably have fewer moral conflicts, which enable them to more consistently embrace traditionally liberal attitudinal positions on diverse social issues. Conservatives, on the other hand, who varied less in their endorsement of 
the various moral foundations, likely have more conflicting moral mandates influencing their attitudes, thus leading to less ideological consistency.

Of course, given the correlational nature of these relationships, we refrain from drawing causal inferences about the relationship between moral foundations and political orientation. The data simply show that the variance shared between moral foundations and political orientation accounts for a significant part of the relationship between political orientation and ideological consistency. Though moral foundations are typically thought of as important determinants of adult political orientation, that emerge relatively early in life and are then edited by socialization experiences across the lifespan, it is also likely that one's political and ideological commitments exert a reciprocal influence on one's later moral concerns. It is important to note, too, that the direct path between political orientation and ideological consistency remained after the indirect effect through VAMF was accounted for. This suggests there are likely other determinants of ideological consistency in addition to variability across moral concerns.

One likely possibility for an additional determinant of ideological consistency is the centrality of one's political orientation to one's social identity. To the extent that social identity provides meaning, structure, and value (self-esteem) to one's self (Tajfel \& Turner, 1985), one would expect that the more central one's political orientation is to one's social identity, the more one's attitudes would coalesce around those associated with that ideology. Investigating the relationship between the centrality of political orientation to one's social identity and ideological consistency seems a promising avenue for future research on these issues.

As noted previously, both we and all other social psychologists with whom we discussed this study were surprised that liberals were more ideologically consistent than conservatives; the 
lay sample asked to predict these results similarly expected greater consistency among conservatives. These intuitions likely resulted, at least in part, from the large body of research documenting greater need for structure and dogmatism and lower openness to experience and cognitive flexibility among conservatives than liberals, and perhaps informal observations consistent with these findings. It may be, however, that these dispositions produce a tendency toward ideological consistency only when people are aware of the ideological inconsistencies among their attitudes. It may be that participants in these studies were not consciously aware of whatever ideological inconsistency may have existed. It may also be that many or most people prefer to think of themselves as independent thinkers who do not toe party lines in the attitudes they endorse. This could lead their moral intuitions to outweigh any influence ideological commitments and personality variables play in determining their attitudes. The roles of conscious awareness of inconsistencies amongst one's political attitudes and self-perceptions of being an independent thinker are other potentially valuable directions for future research.

The present finding that contemporary American conservatives are more ideologically diverse than liberals runs counter to the idea that the liberal movement provides a metaphorical "big tent" that encompasses an especially broad range of diverse people and concerns. It seems fairly clear that the liberal-leaning American Democratic Party is demographically more diverse, appealing to a broader range of races, ethnic and minority groups, women, and otherwise marginalized people (Homan, 2012). But as Haidt, Rosenberg, and Hom (2003) have pointed out, demographic diversity does not necessarily equate to diverse attitudes and values. Their work shows that demographic and moral diversity are quite distinct and influence interpersonal attraction in different ways. In a related vein, Iyer, Koleva, Graham, Ditto, and Haidt (2012) 
have shown that libertarians, who gravitate more toward the Republican than Democratic Party, are distinct in many ways from both conservatives and liberals. The growing libertarian movement might thus have introduced even more ideological diversity into the Republican Party.

The present findings show that, despite their greater demographic diversity, contemporary American liberals show more inter-issue ideological consistency than their conservative counterparts. This might reflect the narrower ranger of moral foundations that people who are drawn to liberal ideology tend to endorse, reflected by the greater VAMF they exhibited in Study 4. These findings also fit well with recent discussions of dissent within conservative ranks regarding their core message and how aspects of the conservative agenda that have broad appeal might be used to sway voters in light of other, logically independent aspects of this ideology, that are off-putting to many voters (Siddiqui, 2012; Von Drehle, 2012). It may be that contemporary liberal ideology is inherently more ideologically consistent than conservative ideology in that it draws on a narrower ranger of moral concerns that conservativism. This is consistent with the idea that contemporary American conservativism reflects a more coalition of more diverse interest groups than contemporary American liberalism.

Assessing ideological consistency in the present studies by computing within-participant standard deviations across diverse attitude issues diverges from the far more typical approach of assessing mean responses to different items for each participant. Though occasionally used in other research, (e.g. research on stability of self-esteem over time; Kernis 2005), withinindividual variability measures are rare. In most research, multiple items assessing different aspects of a conceptual variable are assessed, with the intent of averaging them to get a better estimate of participants' standing on that dimension. However, in this research we measured 
ideological consistency, by assessing within-individual variability in attitudes across diverse issues relevant to political ideology. We therefore sought an array of diverse items tapping diverse attitudes with clear liberal and conservative positions, rather than the same attitudes expressed in different ways. Thus, in the present studies, the extent of within-participant variability was the conceptual variable of interest, rather than an indicator of a reliable (and potentially valid) measure. Though in most research, high reliability across items is a requisite for a useful measure, this was not particularly desirable for our purposes, which requires variability in these within-person variability scores across individuals. The fact that mean responses to these attitudinal items were strongly correlated with self-reported political orientation and past voting behavior in all four studies shows that the items used in our measures do indeed validly align with liberal and conservative political orientations. We suspect that measures of within-participant variability could be useful in other areas of psychological and political research; for example, within participant consistency in voting for candidates of the same party in a given election, or consistency across different elections might provide useful insight into other aspects of political decision-making. The present research, along with the work of Kernis (2005) and others, suggests that exploring the relationship between within-individual consistency and other psychological phenomena may yield valuable insights not obtainable with more traditional approaches to measurement.

Whereas Studies 1 and 2 were conducted on college student samples, Study 3 was conducted with a sample from Amazon's Mechanical Turk and Study 4 was conducted with a sample from the yourmorals.org website. Each of these samples has limitations. Student samples typically are younger, less diverse than the general population, of higher socio-economic status 
and include people motivated and qualified to pursue higher education. Mechanical Turk samples have the potential to be more diverse than college samples, but have been criticized as being notably younger and more liberal than the general public, having more experience with and greater understanding of research, and sometimes even knowledge of the specifics of studies gained by participating in online forums, or misrepresenting their nationality to qualify for participation and payment (Berinsky, Huber, \& Lenz, 2012; Chandler, Mueller, \& Paolacci, 2014; Rand, 2012). The yourmorals.org sample is subject to many of the same criticisms; and this sample was the most skewed toward liberal political orientation of those reported here, only 278 of its 1478 participants categorized themselves as conservative, though this still provides a respectable sample of conservatives. The other samples in our research had more even distribution of participants across the political spectrum. Still, these limitations should be kept in mind when drawing conclusions from this research.

It is also important to note that, although the findings were highly consistent across four studies with different samples and measures, the present findings reflect ideological consistency among Americans at a particular point in time. Whether these findings generalize to other countries and cultures, with different political systems and focal issues, is an important question for future research. It is also unclear at this point whether liberals' higher levels of ideological consistency than conservatives reflect something inherent in their ideology or forces specific to this historical era. This too is an important question for future research.

\section{In Conclusion}

Attitudes toward seemingly unrelated issues, such as reproductive rights, climate change, immigration, war, and taxes are often strongly related to each other. These relationships across 
logically independent issues reflect the structuring power of political ideology. The present findings show that people vary in the extent of consistency imposed by their political ideology and that this consistency varies as a function of ideological self-identification, party affiliation, and past voting behavior. Liberals consistently exhibited higher levels of ideological consistency than conservatives across four studies with diverse samples and measures. This difference was mediated by liberals' tendency to be more variable than conservatives in the moral foundations they endorse. Because liberals prioritize harm and fairness over the other three moral foundations, their attitudes are presumably pulled in fewer directions than conservatives, who show put more equal value on all five of the moral foundations (lower VAMF).

Many interesting and potentially important questions arise from the current research for both psychologists and political scientists: How does ideological consistency relate to the likelihood of voting and other indicators of political involvement? What impact does it have on openness to new information, ideas, and persuasion? How do salient world events affect ideological consistency? Is ideological consistency a good thing for political movements and society in general, or does it lead to unproductive political gridlock? We hope these findings will be an impetus for further research on these issues, exploring other antecedents and consequences of the extent of coherence within the political attitudes that people hold. 


\section{References}

Aiken, L. S., \& West, S. G. (1991). Multiple regression: Testing and interpreting interactions. Newbury Park, CA: Sage.

Barton, A. H., \& Parsons, R.W. (1977). Measuring belief system structure. Public Opinion Quarterly, 41, 159-180. doi:10.1086/268372

Baumeister, R. F. (1991). Meanings of life. New York: Guilford Press.

Berinsky, A. J., Huber, G. A., \& Lenz, G. S. (2012). Evaluating online labor markets for experimental research: Amazon. com's Mechanical Turk. Political Analysis, 20, 351-368. doi:10.1093/pan/mpr057

Bufkin, S. (2012, November 13). Karl Rove calls for Republicans to replicate Howard Dean's 50-state strategy. The Huffington Post. Retrieved February 4, 2013 from http://www.huffingtonpost.com/2012/11/13/karl-rove-howard-deanstrategy_n_2122459.html

Chandler, J., Mueller, P., \& Paolacci, G. (2014). Nonnaïveté among Amazon Mechanical Turk workers: Consequences and solutions for behavioral researchers. Behavior Research Methods, 46, 112-130. doi:10.3758/s13428-013-0365-7

Clifford, S., Jerit, J., Rainey, C., \& Motyl, M. (2015). Moral concerns and policy attitudes: Investigating the influence of elite rhetoric. Political Communication, 32, 229-248. doi: $10.1080 / 10584609.2014 .944320$

Cohen, G. L. (2003). Party over policy: The dominating impact of group influence on political beliefs. Journal of Personality and Social Psychology, 85, 808-822. doi:10.1037/00223514.85.5.808 
Converse, P. E. (1964). The nature of belief systems in mass publics. In D. E. Apter (Ed.), Ideology and discontent (pp. 206 -261). New York: Free Press.

Crowson, H. M. (2009). Are all conservatives alike? A study of the psychological correlates of cultural and economic conservatism. The Journal of Psychology: Interdisciplinary and Applied, 143, 449-463. doi:10.3200/JRL.143.5.449-463

Feldman, S. (2003). Values, ideology, and the structure of political attitudes. In D. O. Sears, L. Huddy, \& R. Jervis (Eds.), The Oxford handbook of political psychology (pp. 477-508). New York: Oxford University Press.

Feldman, S., \& Johnston, C. (2009, September). Understanding political ideology. Paper presented at the annual meeting of the American Political Science Association, Toronto, Canada.

Frimer, J. A., Tell, C. E., \& Motyl, M. (2016). Sacralizing liberals and fair-minded conservatives: Ideological symmetry in the moral motives in the culture war. Analyses of Social Issues and Public Policy. doi: 10.1111/asap.12127

Gerring, J. (1997). Ideology: A definitional analysis. Political Research Quarterly, 50, 957-994. doi:10.1177/106591299705000412

Gottfried, P. E. (2009). Conservatism in America: Making sense of the American Right. New York: Palgrave Macmillan.

Graham, J., \& Haidt, J. (2010). Beyond beliefs: Religions bind individuals into moral communities. Personality and Social Psychology Review, 14, 140-150. doi:10.1177/ 1088868309353415 
Graham, J., Haidt, J., Koleva, S., Motyl, M., Iyer, R., Wojcik, S. P., \& Ditto, P. H. (2013). Moral foundations theory: The pragmatic validity of moral pluralism. Advances in Experimental Social Psychology, 47, 55-130. doi:10.1016/B978-0-12-407236-7.00002-4

Graham, J., Haidt, J. \& Nosek, B.A. (2009). Liberals and conservatives rely on different sets of moral foundations. Journal of Personality and Social Psychology, 96, 1029-1046. doi: $10.1037 / \mathrm{a} 0015141$

Graham, J., Nosek, B. A., Haidt, J., Iyer, R., Koleva, S., \& Ditto, P. H. (2011). Mapping the moral domain. Journal of Personality and Social Psychology, 101, 366-385. doi: $10.1037 / \mathrm{a} 0021847$

Haidt, J., \& Graham, J. (2007). When morality opposes justice: Conservatives have moral intuitions that liberals may not recognize. Social Justice Research, 20, 98-116. doi:10.1007/s11211-007-0034-z

Haidt, J., \& Joseph, C. (2004). Intuitive ethics: How innately prepared intuitions generate culturally variable virtues. Daedalus, Fall, 55-66. doi:10.1162/0011526042365555

Haidt, J., Rosenberg, E., \& Hom, H. (2003). Differentiating diversities: Moral diversity is not like other kinds. Journal of Applied Social Psychology, 33, 1-36. doi:10.1111/j.15591816.2003.tb02071.x.

Hawkins, C. B., \& Nosek, B. A. (2012). Motivated independence? Implicit party identity predicts political judgments among self-proclaimed independents. Personality and Social Psychology Bulletin, 38, 1437-1452. doi: 10.1177/0146167212452313

Hayes, A. F. (2013). Introduction to mediation, moderation, and conditional process analysis: A regression-based approach. New York: Guilford Press. 
Hennes, E. P., Nam, H. H., Stern, C., \& Jost, J. T. (2012). Not all ideologies are created equal: Epistemic, existential, and relational needs predict system-justifying attitudes. Social Cognition, 30, 669-688. doi:10.1521/soco.2012.30.6.669

Homan, T. R. (2012, November 8). White guys running the US House face diverse Democrats. Bloomberg. Retrieved February 4, 2013 from http://www.bloomberg.com/news/2012-1108/women-and-minorities-to-dominate-house-democratic-party.html

Huntington, S. (1957). Conservatism as an ideology. American Political Science Review, 51, 454-473. doi: $10.2307 / 1952202$

Iyer, R., Koleva, S., Graham, J., Ditto, P., \& Haidt, J. (2012). Understanding libertarian morality: The psychological dispositions of self-identified libertarians. PLoS ONE, 7(8): e42366. doi:10.1371/journal.pone.0042366

Jacoby, W. G. (1991). Ideological identification and issue attitudes. American Journal of Political Science, 35, 178-205. doi: 10.2307/2111443

Janoff-Bulman, R. (2009). Political attitudes and complexity: Responses from a motivational perspective. Psychological Inquiry, 20, 177-182. doi:10.1080/ 10478400903028672

Janoff-Bulman, R., Sheikh, S., \& Baldacci, K. (2008). Mapping moral motives: Approach, avoidance and political orientation. Journal of Experimental Social Psychology, 44, 1091-1099. doi:10.1016/j.jesp.2007.11.003

Jennings, M. K. (1992). Ideology among mass publics and political elites. Public Opinion Quarterly, 56, 419-441. doi:10.1086/269335

Jost, J. T. (2006). The end of the end of ideology. American Psychologist, 61, 651-670. doi:10.1037/0003-066X.61.7.651 
Jost, J. T., Federico, C. M., \& Napier, J. L. (2009). Political ideology: Its structure, functions, and elective affinities. Annual Review of Psychology, 60, 307-337. doi:10.1177/ 0146167211406508

Jost, J. T., Glaser, J., Kruglanski, A. W., \& Sulloway, F. (2003). Political conservatism as motivated social cognition. Psychological Bulletin, 129, 339-375. doi:10.1037/00332909.129.3.339

Jost, J. T., Ledgerwood, A., \& Hardin, C.D. (2007). Shared reality, system verification, and the relational basis of ideological beliefs. Social and Personality Psychology Compass, 2, 171-186. doi:10.1111/j.1751-9004.2007.00056

Judd, C. M., Krosnick, J. A., \& Milburn, M. A. (1981). Political involvement in attitude structure in the general public. American Sociological Review, 46, 660-669. Retrieved from http://www.jstor.org/stable/2094947

Kernis, M. H. (2005). Measuring self-esteem in context: The importance of stability of selfesteem in psychological functioning. Journal of Personality, 73, 1569-1605. doi: 10.1111/j.1467-6494.2005.00359.x

Kinder, D. R. (1998). Opinion and action in the realm of politics. In D. T. Gilbert, S. T. Fiske, \& G. Lindzey (Eds.) Handbook of social psychology (4 ${ }^{\text {th }}$ ed.) (pp. 778-867). Boston, MA: McGraw-Hill.

Kinder, D. R., \& Sears, D. O. (1985). Public opinion and political action. In G. Lindzey \& E. Aronson (Eds.), Handbook of social psychology (3 ${ }^{\text {rd }}$ ed.) (pp. 659-741). New York: Random House. 
Knight, K. (2006). Transformations of the concept of ideology in the twentieth century. American Political Science Review, 100, 619-626. doi:10.1017/S0003055406062502

Lewis-Beck, M., Jacoby, W., Norpoth, H., Weisberg, H. (2008). The American voter revisited. Ann Arbor: University of Michigan Press.

Motyl, M. (2014). "If he wins, I'm moving to Canada": Ideological migration threats following the 2012 US Presidential Election. Analyses of Social Issues and Public Policy, 14(1), 123-136.

Motyl, M. (2016). Liberals and conservatives are (geographically) dividing. In J. Graham \& P. Valdesolo (eds.), Social Psychology of Political Polarization.

Motyl, M., \& Iyer, R. (2014). Will the real fundamental difference underlying ideology please stand up?. Behavioral and Brain Sciences, 37(3), 322-323.

Motyl, M., Iyer, R., Oishi, S., Trawalter, S., \& Nosek, B. A. (2014). How ideological migration geographically segregates groups. Journal of Experimental Social Psychology, 51, 1-14. doi: $10.1016 /$ j.jesp.2013.10.010

Motyl, M., Iyer, R., \& Graham, J. (2013). Self-reported ideology: The best predictor of the most outcome variables? Unpublished manuscript.

Muller, J. Z. (1997). What is conservative social and political thought? In J. Z. Muller (Ed.), Conservatism: An anthology of social and political thought from David Hume to the present (pp. 3-31). Princeton, NJ: Princeton University Press.

Nosek, B. A., Banaji, M. R., \& Jost, J. T. (2009). The politics of intergroup attitudes. In J. T. Jost, A. C. Kay, \& H. Thorisdottir (Eds.). Social and psychological bases of ideology and system justification (pp. 480-506). New York: Oxford University Press. 
Preacher, K. J., \& Kelley, K. (2011). Effect size measures for mediation models: quantitative strategies for communicating indirect effects. Psychological Methods, 16(2), 93-115. doi: $10.1037 / \mathrm{a} 0022658$

Rand, D. G. (2012). The promise of Mechanical Turk: How online labor markets can help theorists run behavioral experiments. Journal of Theoretical Biology, 299, 172-179. doi: 10.1016/j.jtbi.2011.03.004

Siddiqui, S. (2012, November, 9). Conservatives struggle to explain how Mitt Romney lost 2012 Presidential election. Huffington Post. Retrieved February 4, 2013 from http://www.huffingtonpost.com/2012/11/09/conservatives-mitt-romney-presidentialelection_n_2099504.html

Smith, T. W. (1990). Liberal and conservative trends in the United States since World War II. Public Opinion Quarterly, 54(4), 479-507. doi:10.1086/269224

Sniderman, P. M., \& Bullock, J. G. (2004). A consistency theory of public opinion and political choice: The hypothesis of menu dependence. In W. E. Saris and P. M. Sniderman (Eds.), Studies in public opinion: Gauging attitudes, nonattitudes, measurement error, and change (pp. 337-357). Princeton, NJ: Princeton University Press.

Stenner, K. (2009). Three kinds of “conservatism”. Psychological Inquiry, 20, 142-159. doi:10.1080/10478400903028615

Sugar, J. A., Viney, W., \& Rohe, J. (1992). A comparison of contemporary and historical conservatism. The Journal of General Psychology, 119, 89-97. doi:10.1080/ 00221309.1992 .9921161 
Tajfel, H., \& Turner, J. C. (1985). The social identity theory of intergroup behavior. In S. Worchel \& W. G. Austin (Eds.), Psychology of intergroup relations (2nd ed., pp. 7-24). Chicago: Nelson-Hall.

Tetlock, P. E. (1984). Cognitive style and political belief systems in the British House of Commons. Journal of Personality and Social Psychology, 46, 365-375. doi:10.1037/ $0022-3514.46 .2 .365$

Tetlock P. E. (2007). Psychology and politics: The challenges of integrating across levels of analysis in social science. In Kruglanski A. W., Higgins E. T. (Eds.), Social psychology: Handbook of basic principles (2 ${ }^{\text {nd }}$ ed., pp. 888-912). New York: Guilford.

Von Drehle, D. (2012, February 13). The conservative identity crisis. Time. Retrieved January 31, 2013, from http:/www.time.com/time/magazine/article/0,9171,2105970,00.html

Weber, C. R., \& Federico, C. M. (2013). Moral foundations and heterogeneity in ideological preferences. Political Psychology, 34, 107-126. doi: 10.1111/j.1467-9221.2012.00922.x

Zell, E., \& Bernstein, M. J. (2013). You may think you're right... Young adults are more liberal than they realize. Social Psychological and Personality Science. doi: 10.1111/j.20448260.1968.tb00568.x. 
Footnotes

${ }^{1}$ Parallel analyses in all studies revealed that all three political orientation measures correlated with scores on the various PAQ measures, indicating that the orientation measures predicted specific attitudes in line with participants' orientation, and consequently, provide validation of the items ideological content. To avoid redundancy, only analyses of the continuous political orientation measure are reported for subsequent studies. Details of these analyses will be provided by the authors on request.

${ }^{2}$ Because parallel analyses using self-reported political party or candidate choice in the 2008 US presidential elections revealed the same pattern of significant results as self-reported political affiliation on our ideological consistency measures in all studies, these analyses are not reported here but are available from the authors on request.

${ }^{3}$ Mauchly's test indicated that the assumption of sphericity had been violated, $\chi^{2}(9)=855.36, p<.001$. Degrees of freedom were corrected using Huynh-Feldt estimates of sphericity $(\varepsilon=.76)$. 
Table 1

Means and Standard Deviations by Political Identification Across the Five Moral Foundations

\begin{tabular}{|c|c|c|c|}
\hline \multicolumn{2}{|c|}{$\begin{array}{c}\text { Moral } \\
\text { Foundation }\end{array}$} & \multirow[b]{2}{*}{$M$} & \multirow[b]{2}{*}{$S D$} \\
\hline & $\begin{array}{c}\text { Political } \\
\text { Identification }\end{array}$ & & \\
\hline \multicolumn{4}{|l|}{ Harm } \\
\hline & Liberal & 3.73 & 0.72 \\
\hline & Moderate & 3.30 & 0.97 \\
\hline & Conservative & 2.89 & 0.92 \\
\hline \multicolumn{4}{|c|}{ Fairness } \\
\hline & Liberal & 3.82 & 0.63 \\
\hline & Moderate & 3.41 & 0.70 \\
\hline & Conservative & 2.99 & 0.75 \\
\hline \multicolumn{4}{|c|}{ Ingroup } \\
\hline & Liberal & 2.02 & 0.78 \\
\hline & Moderate & 2.59 & 0.81 \\
\hline & Conservative & 3.05 & 0.76 \\
\hline \multicolumn{4}{|c|}{ Authority } \\
\hline & Liberal & 1.97 & 0.83 \\
\hline & Moderate & 2.61 & 0.79 \\
\hline & Conservative & 3.21 & 0.71 \\
\hline \multicolumn{4}{|l|}{ Purity } \\
\hline & Liberal & 1.24 & 0.89 \\
\hline & Moderate & 1.89 & 1.15 \\
\hline & Conservative & 2.88 & 1.09 \\
\hline
\end{tabular}

$\overline{\text { Note. Liberal }(n=1074) \text {; moderate }(n=155) \text {; conservative }}$ $(n=248)$. 
Table 2

Planned Contrasts of Political Identification Across the Five Moral Foundations

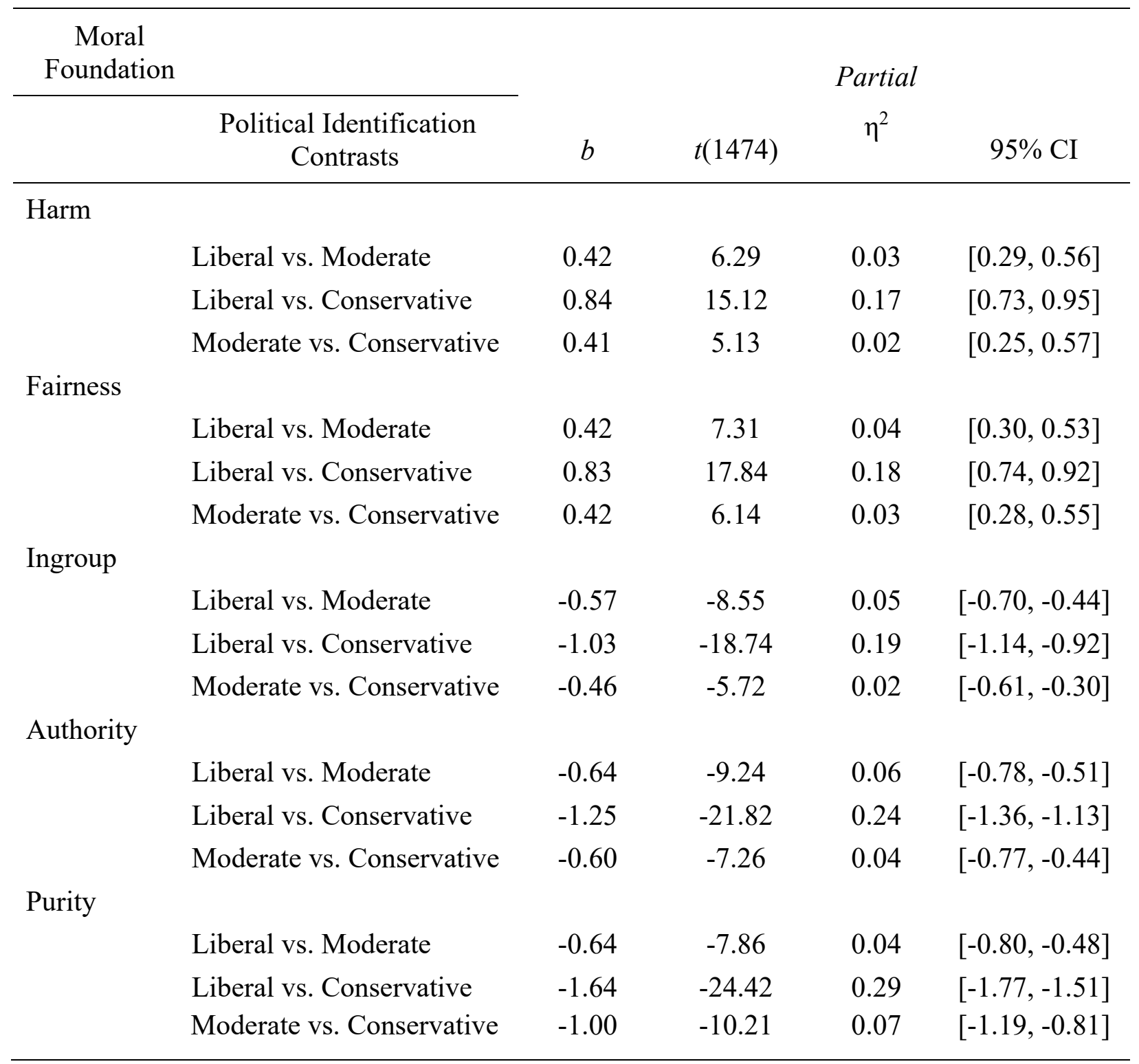

Note. $b=$ unstandardized beta; $\mathrm{CI}=$ confidence interval.

All analyses are significant at the $p<.001$ level. 
Table 3

Multiple Regression of the effects of Political Orientation and Moral Foundation Endorsement on Ideological Consistency Scores

\begin{tabular}{lcccccc}
\hline \multicolumn{1}{c}{ Predictor } & $B$ & $S E$ & $\beta$ & $t(1470)$ & $P$ & $95 \% \mathrm{CI}$ \\
\hline $\begin{array}{l}\text { Self-reported political } \\
\text { orientation }\end{array}$ & .13 & .01 & .32 & 9.70 & $<.001$ & {$[.10, .15]$} \\
$\begin{array}{l}\text { Moral Foundation: } \\
\text { Harm }\end{array}$ & -.09 & .02 & -.12 & -4.50 & $<.001$ & {$[-.13,-.05]$} \\
$\quad$ Fairness & -.02 & .02 & -.02 & -0.85 & .40 & {$[-.07, .03]$} \\
$\quad$ Ingroup & -.00 & .02 & -.00 & -0.13 & .89 & {$[-.05, .04]$} \\
$\quad$ Authority & .06 & .02 & .09 & 2.47 & .01 & {$[.01, .10]$} \\
$\quad$ Purity & .09 & .02 & .15 & 4.59 & $<.001$ & {$[.05, .12]$} \\
\hline
\end{tabular}

Note: $b=$ unstandardized beta coefficient; $\beta=$ standardized coefficient; $\mathrm{CI}=$ confidence interval. Predictors mean-centered prior to analysis; entry method used for analysis. 


\section{Figure Captions}

Figure 1. Mediation model of the effect of political orientation on ideological consistency through variability across moral foundations (VAMF). Higher scores on political orientation represent greater self-reported conservatism; higher scores on VAMF and ideological consistency represent less consistency (greater within-participant variability). Unstandardized coefficients are presented; the confidence interval for the indirect effect is a bias corrected (BCa) bootstrapped confidence interval (CI) based on 10,000 samples.

Figure 2. Mean endorsement across each of the five moral foundations by self-reported political identification category. Higher scores on each foundation indicate greater endorsement of the foundation. 
Fig. 1

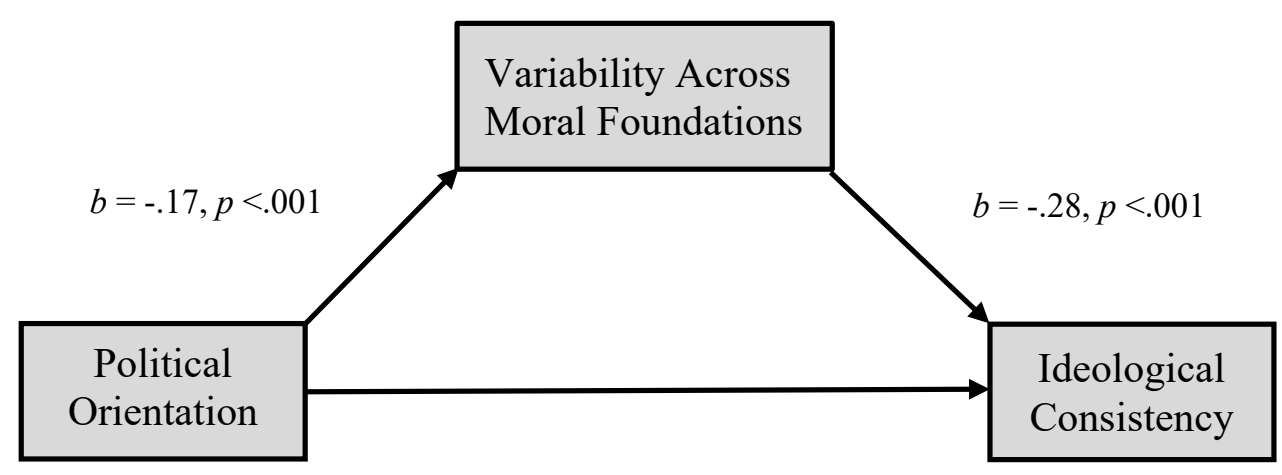

Direct effect, $b=.15, p<.001$

Indirect effect, $b=.05,95 \%$ CI $[.09, .15]$ 
Fig. 2

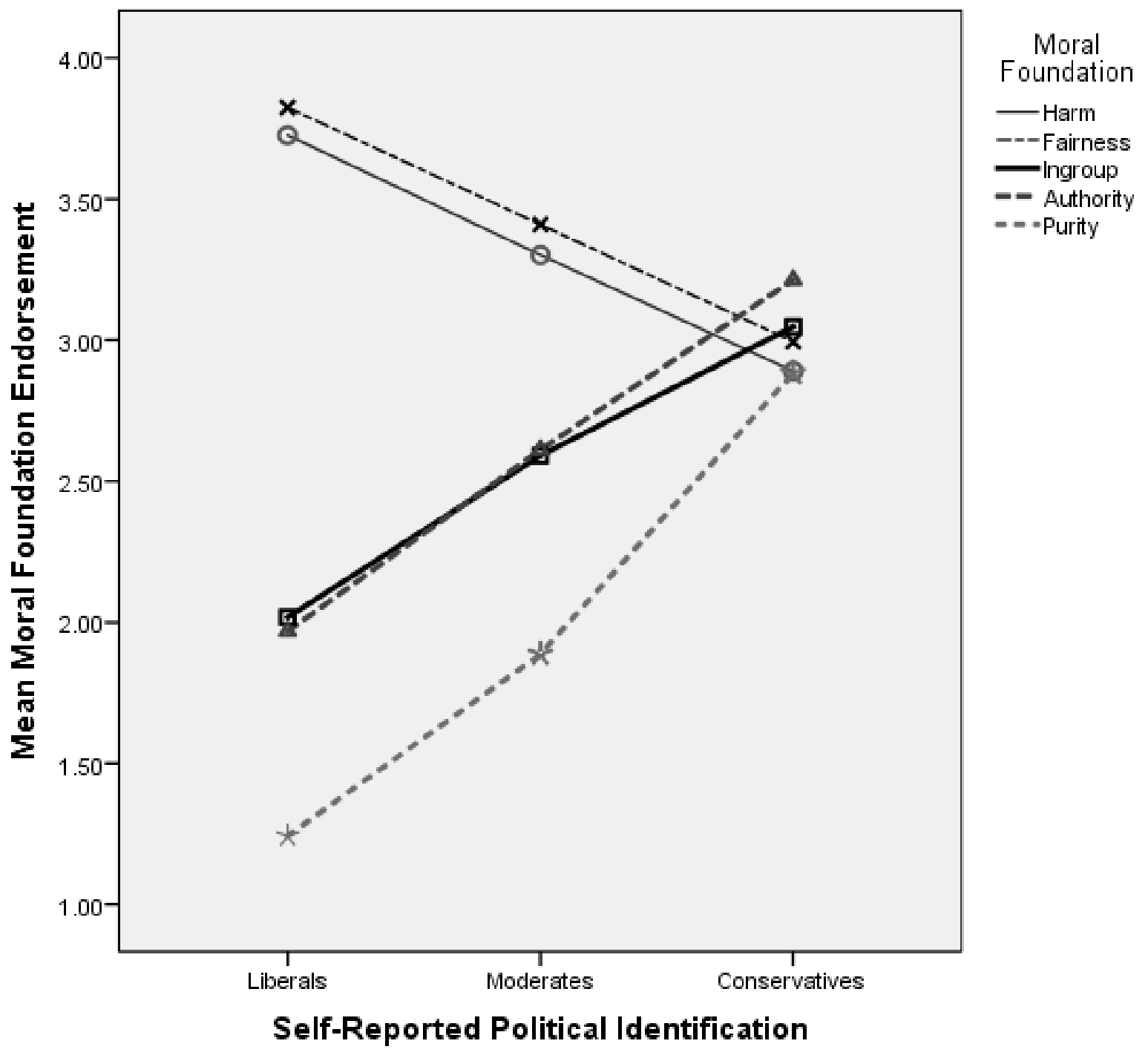




\section{Appendix A}

\section{Political Attitudes Questionnaire (Studies 1 and 2)}

1) It is the responsibility of political leaders to promote programs that will help close the income gap between the rich and the poor.

2) There is no "right way" to live life; instead, everyone must create a way to live which works best for them.

3) Spending tax dollars on "abstinence education" rather than "sex education" is more effective in curbing teen pregnancy.

4) The more money a person makes in America, the more taxes he/she should pay.

5) The use of our military strength makes the United States a safer place to live.

6) America would be a better place if people had stronger religious beliefs.

7) The traditional (male/female) two-parent family provides the best environment of stability, discipline, responsibility and character.

8) America's domestic policy should do more to ensure that living and working conditions are equal for all groups of people.

9) Flag burning should be illegal.

10) Our society is set up so that people usually get what they deserve.

11) Taxation should be used to fund social programs.

12) Gay marriage threatens the sanctity of marriage. 


\section{Appendix B}

\section{Political Attitudes Questionnaire II (Study 3)}

1) The government should avoid promoting religion in any way.

2) The federal government should regulate power plants, cars, and factories to reduce global warming.

3) Marriage should only be allowed between a man and a woman.

4) A woman should be able to get an abortion if she decides she wants one.

5) The government should provide equal health care benefits for all, regardless of their ability to pay.

6) We need stricter gun control laws to reduce the amount of violent crime in this country.

7) Increases in the Earth's temperature over the last century are due more to natural changes in the environment than to human pollution.

8) It is the government's responsibility to provide financial assistance to people living in poverty.

9) No matter how ill, people do not have the right to end their lives.

10) Executing people who commit murder is the best way to deter others from committing murder.

11) American military action in Iraq was a huge mistake.

12) Any law limiting gun ownership infringes on basic rights that all Americans should have.

13) It would be wrong for a group of Muslims to build a mosque and Islamic cultural center a few blocks from the site of the September 11 terrorist attacks in New York City.

14) It is essential that we use alternative energy sources such as wind and solar power to replace our use of oil as soon as possible.

15) We should allow the Muslims to build a mosque and Islamic cultural center near the World Trade Center site to serve as a symbol of America's religious tolerance.

16) A public school or government building should be able to display a monument with a religious verse from the Bible.

17) A person should have the right to a physician-assisted suicide if they so choose.

18) Abortion should be illegal in all circumstances.

19) The death penalty is immoral and should be abolished entirely.

20) The government should put more Border Patrol and federal law enforcement agents on the U.S. border with Mexico in order to stem the flow of illegal immigrants across the border.

21) Gays and lesbians should have the right to get married and have their marriage recognized by law as valid.

22) Oil drilling should be increased both on land and at sea to create lower prices and lessen our dependence on other countries for oil.

23) Enhanced interrogation techniques, such as water-boarding, stress positions, and sleep deprivation, are torture and should never be used.

24) The government should keep out of health care.

25) The new immigration law in AZ that requires proof of US citizenship from people suspected of being illegal immigrants is an unfair and discriminatory policy. 
26) Welfare and other social programs should be abolished.

27) The Bush administration's policies on terrorism have made the country more secure over years since $9 / 11$.

28) The government is justified in approving the use of harsh interrogation techniques to get information from possible terrorists. 


\section{Appendix C \\ Political Attitudes Questionnaire III (Study 4)}

1) Do you support or oppose police verification of immigration status?

1 (strongly oppose) to 7 (strongly support) $\mathbf{R}$

2) Do you support or oppose a woman's choice to have an abortion?

1 (strongly oppose) to 7 (strongly support) $\mathbf{R}$

3) Do you support or oppose the legalization of marijuana use?

1 (strongly oppose) to 7 (strongly support) $\mathbf{R}$

4) Do you support or oppose allowing gay and lesbian couples to enter into same-sex marriage?

1 (strongly oppose) to 7 (strongly support) $\mathbf{R}$

5) Is your opinion of offshore drilling favorable or unfavorable?

1 (very unfavorable) to 7 (very favorable)

6) Do you feel immigration is a good thing?

1 (a very good thing) to 7 (a very bad thing)

7) Do you feel bank regulation is a good idea?

1 (a very good idea) to 7 (a very bad idea)

8) Is your opinion of a mosque being built near the site of the former World Trade Center favorable or unfavorable?

1 (very unfavorable) to 7 (very favorable) $\mathbf{R}$

$\mathbf{R}=$ reverse scored 